\title{
Anionic surfactants enhance click reaction-mediated protein conjugation with ubiquitin
}

\author{
Daniel Schneider ${ }^{\dagger}$, Tatjana Schneider ${ }^{\dagger}$, Joos Aschenbrenner, Franziska Mortensen, Martin Scheffner* \\ Andreas Marx* \\ Department of Chemistry, Konstanz Research School Chemical Biology, University of Konstanz, 78457 Konstanz, Germany \\ Department of Biology, Konstanz Research School Chemical Biology, University of Konstanz, 78457 Konstanz, Germany
}

\section{A R T I C L E I N F O}

Keywords:

Ubiquitin

Click reaction

Surfactants

Bioorthogonal chemistry

Protein conjugation

\begin{abstract}
A B S T R A C T
The $\mathrm{Cu}(\mathrm{I})$ catalyzed alkyne azide cycloaddition (CuAAC) has become increasingly important in the con jugation chemistry of biomolecules. For example, it is an efficient and convenient method to generate defined ubiquitin protein conjugates. Here, we investigate the effect of surfactants on the efficiency of CuAAC for chemical protein ubiquitylation. We found that anionic surfactants enhance conjugate forma tion by up to 10 fold resulting in high yields even at low (i.e., micromolar) concentrations of the reac tants. Notably, the herein investigated conjugates are functional and thus properly folded.
\end{abstract}

\section{Introduction}

Click chemistry represents a powerful synthetic method inspired by nature's strategy to use simple building blocks for gen erating large oligomers with remarkable modularity and diver sity. ${ }^{1-4}$ Click chemistry employs functional groups that are easy to synthesize and enable highly reliable, rapid and selective reactions. $^{2}$

The prime example of click chemistry is the $\mathrm{Cu}(\mathrm{I})$ catalyzed cycloaddition of azides and alkynes (CuAAC). ${ }^{5-7}$ CuAAC relies on a 1,3 dipolar cycloaddition to yield 1,2,3 triazoles $^{5}$ and proceeds significantly accelerated and with almost complete regioselectivity for 1,4 disubstituted triazoles under $\mathrm{Cu}(\mathrm{I})$ catalysis. ${ }^{6,7}$ The reaction requires no protection groups since the reactive moieties, azides and terminal alkynes, are orthogonal to a wide variety of functional groups and have great kinetic stability. Referred to as 'the' click reaction, CuAAC has proven itself as extremely versatile and pro moted efforts in key areas like bioconjugation, ${ }^{8-12}$ materials science $^{13-17}$ and drug discovery. ${ }^{18-22}$

The chemical properties of 1,2,3 triazoles render the click reac tion applicable in the context of biomolecules. The heterocycle is water soluble and mimics certain aspects of the natural peptide

\footnotetext{
* Corresponding authors. Tel.: +49 753188 5139; fax: +49 7531885140 .

E-mail addresses: martin.scheffner@uni-konstanz.de (M. Scheffner), andreas. marx@uni-konstanz.de (A. Marx).

$\dagger$ Contributed equally to the work.
}

bond by offering similar electronic properties and configuration of atoms. ${ }^{23-28}$ Notably, it is not susceptible to hydrolytic cleavage. Indeed, several members of the 1,2,3 triazole family have been shown to be biologically active in terms of cytokine inhibition, ${ }^{29,30}$ antiviral activity ${ }^{31-33}$ or anti bacterial activity ${ }^{34}$ highlighting their cellular stability.

Together with the aforementioned favorable characteristics of $1,2,3$ triazoles, the bioorthogonality of the click reaction renders it a very valuable strategy for bioconjugation. Indeed, CuAAC has been employed to attach various small compounds to biomole cules like peptides, ${ }^{9,35}$ oligosaccharides, ${ }^{36,37}$ virus particles ${ }^{12,29}$ or $\mathrm{DNA}^{38}$ and the respective conjugates have been very useful for studying biological processes. ${ }^{39-42}$ Also, CuAAC contributed to novel applications in immobilization of carbohydrates, ${ }^{43,44}$ DNA $^{45,46}$ and proteins ${ }^{44,47,48}$ onto surfaces as well as in activity based protein profiling. ${ }^{40,49}$

Until recently, biomolecules were chemically modified with the respective reactive moiety to allow tagging via click reaction. Nowadays, engineering of natural building blocks like amino acids or nucleotides enables the insertion of a bioorthogonal reactive group via biosynthesis. Along these lines, unnatural amino acids have been used to generate proteins containing azide or alkyne functionalities by expansion of the genetic code. ${ }^{50-52}$ Using such functionalized proteins, it was shown that CuAAC cannot only be used to tag biomolecules with small entities but also to generate protein protein conjugates. ${ }^{53,54}$ We developed a straightforward 
method for the generation of defined mono ubiquitylated conju gates as well as site specifically linked ubiquitin dimers by com bining incorporation of unnatural amino acids and CuAAC.39,55 The resulting bioorthogonally linked proteins were shown to be functional indicating that the method developed is suited to resolve a major bottleneck in ubiquitin research, the lack of avail ability of homogenous populations of defined ubiquitin conjugates for functional characterization. However, product yields were rather low limiting its applicability. In attempts to improve the approach, we realized that addition of the surfactant sodium dode cyl sulfate (SDS) results in a significant increase of the yield of CuAAC. ${ }^{56,57}$ This improvement was crucial, for example, for the generation of site specifically linked poly ubiquitin chains that were used successfully in biochemical assays. ${ }^{41,56}$ In order to gain more insights into this effect, we investigated a variety of surfac tants for their potential to promote CuAAC for the generation of ubiquitin protein conjugates. We observed that a negative charge combined with an alkane chain of certain length is crucial to enhance product formation. Positively charged surfactants showed no impact indicating that partial unfolding of proteins hence, bet ter access to the reactive groups might play role, but is not suffi cient for promoting the reaction or explaining the observed effects.

\section{Results and discussion}

Low, likely sub denaturing concentrations of SDS (i.e., $1 \mathrm{mM}$ ) were found to significantly increase the yield of CuAAC between two suitably functionalized proteins. ${ }^{41,56,57}$ To gain further insight into this effect, we studied other additives (Table 1 ) with respect to their potential to promote product formation. As model systems for bioorthogonal ubiquitylation via CuAAC, modification of human DNA polymerase beta (Pol beta) at position K61 and di ubiquitin formation at position $\mathrm{K} 6$ and $\mathrm{K} 48$, respectively, were investigated. ${ }^{57}$ To generate ubiquitin with a C terminal azide (Ub G76Aha), selec tive pressure incorporation was employed for introduction of the unnatural amino acid azidohomoalanine (Aha) during biosynthesis as described. ${ }^{41,56,57}$ To introduce the alkyne functionality in either Pol beta or ubiquitin, we site specifically replaced the aforemen tioned lysine residues with the propargyl derivatized pyrrolysine analog Plk by amber codon suppression. ${ }^{41,55-57}$

Initially, two cholesterol derivatives, sodium cholate and 3 [(3 cholamidopropyl)dimethylammonio] 1 propanesulfonate (CHAPS), were tested for their influence on the generation of ubiquitin conjugated Pol beta (Pol beta Ub; Fig. 1). For both surfactants no significant effects on reaction yield were observed up to concentrations of $10 \mathrm{mM}$.

As opposed to SDS, cholesterol derivatives do not denature pro teins. ${ }^{58,59}$ Thus, a plausible reason for the beneficial effect of SDS could be that weakening of the conformational rigidity of the pro tein is required, for example, to increase the accessibility and thus

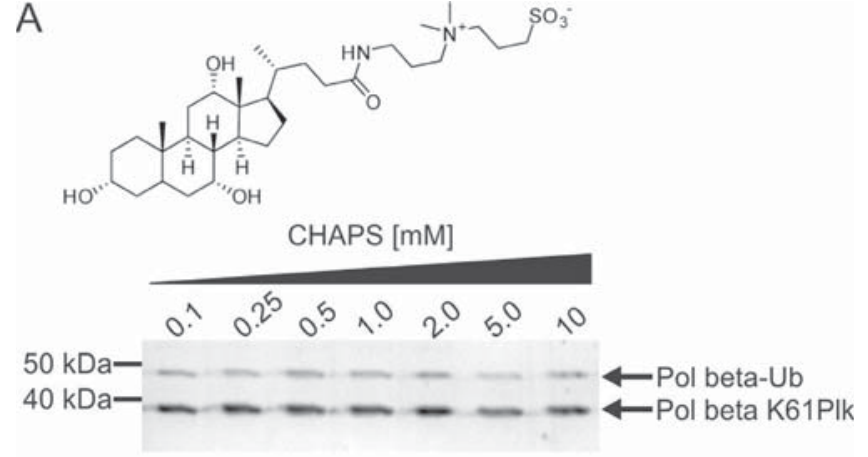

B

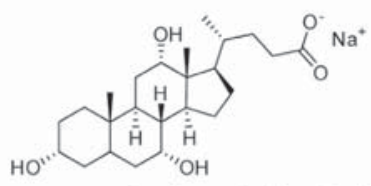

Sodium cholate [mM]

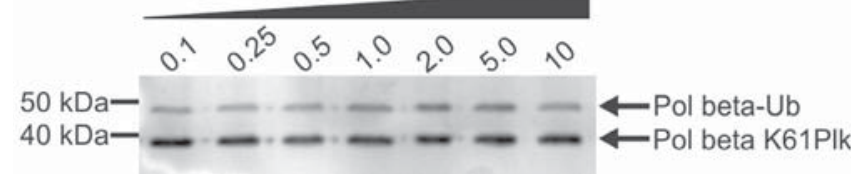

Figure 1. Effect of cholesterol derivatives on click reaction between Pol beta and ubiquitin. (A) Upon addition of the zwitterionic surfactant 3-[(3-Cholamidopropyl)dimethylammoniol-1-propanesulfonate (CHAPS) or (B) the anionic sodium cholate to the click reaction, no increase in product yield was observed compared to the reactions without surfactant. In each case, addition of $1 \mathrm{mM}$ SDS (+SDS) served as positive control for increased conjugate formation. Positions of Pol beta, ubiquitylated Pol beta, and molecular mass markers are indicated.

reactivity of the alkyne and azide groups. To address this hypoth esis, we tested the detergents cetyltrimethylammonium bromide (CTAB) and dodecyltrimethylammonium bromide (DTAB) that like SDS, are known to be able to denature proteins. ${ }^{29,60}$ Structurally, they likewise exhibit a long alkyl chain and a charged head group which, in contrast to SDS, is positively charged (Fig. 2). Similar to cholesterol derivatives, both substances did not promote product formation at all concentrations tested.

Next, sodium dodecyl sulfonate, which is structurally closely related to SDS, was tested for its effect on Pol beta Ub conjugate formation (Fig. 3A). Compared to SDS, sodium dodecyl sulfonate only lacks one oxygen atom and thus exhibits a sulfur carbon link age instead of an oxygen carbon linkage between the charged head group and the alkane tail. With this surfactant, we observed a pos itive effect on Pol beta Ub conjugate formation, comparable to that of SDS (note that due to limited solubility, sodium dodecyl sul fonate could only be added up to a concentration of $3 \mathrm{mM}$, whereas we tested concentrations as high as $10 \mathrm{mM}$ for all other surfactants).

Table 1

Summary of tested detergents and their effect on promoting chemical ubiquitylation

\begin{tabular}{lll}
\hline Detergent & Known characteristics & $\begin{array}{c}\text { Effect on yield of click reaction between } \\
\text { Ub G76Aha and Pol beta K61Plk }\end{array}$ \\
\hline $\begin{array}{l}\text { 3-[(3-Cholamidopropyl)-dimethylammo-nio]- } \\
\text { 1-propanesulfonate (CHAPS) }\end{array}$ & Cholesterol derivative, non-denaturing, zwitterionic & No effect \\
Sodium cholate & Cholesterol derivative, non-denaturing, negatively charged & No effect \\
Cetyltrimethylammonium bromide (CTAB) & Denaturing, positively charged & No effect \\
Dodecyltrimethylammonium bromide (DTAB) & Denaturing, positively charged & No effect \\
Sodium hexyl sulfonate & Negatively charged & No effect \\
Sodium octyl sulfonate & Denaturing, negatively charged & No effect \\
Sodium decyl sulfonate & Denaturing, negatively charged & Slight increase of yield \\
Sodium dodecyl sulfonate & Denaturing, negatively charged & Increase of yield up to $\sim 70 \%$ \\
Sodium dodecyl sulfate (SDS) & Denaturing, negatively charged & Increase of yield up to $\sim 70 \%$ \\
N-Lauroylsarcosine & Denaturing, negatively charged & Increase of yield up to $\sim 100 \%$ \\
\hline
\end{tabular}


A

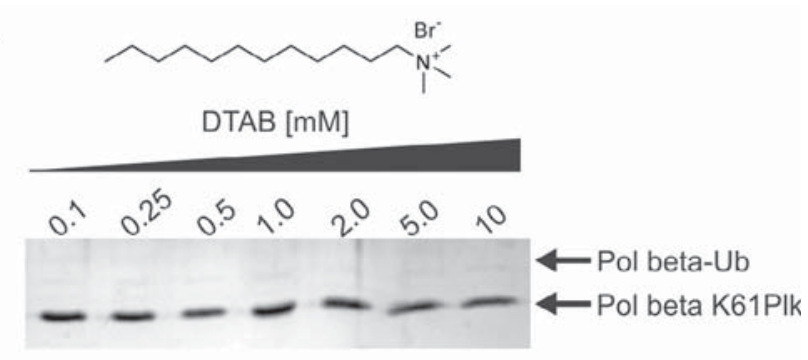

B

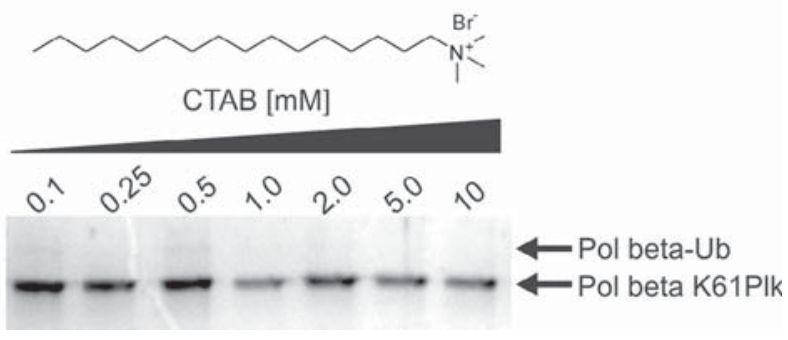

Figure 2. Effect of positively charged alkane surfactants on CuAAC. (A) Dodecyl trimethylammoniumbromide (DTAB) or (B) cetyl trimethylammoniumbromide $(\mathrm{CTAB})$ were included at the indicated concentrations. Positions of Pol beta and ubiquitylated Pol beta are indicated.
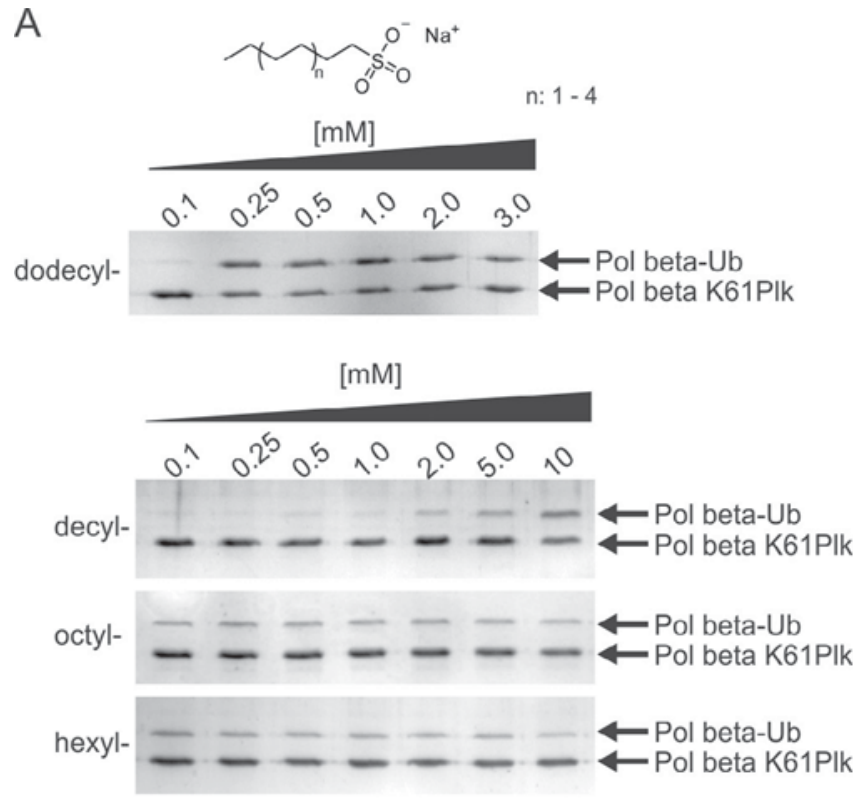

B

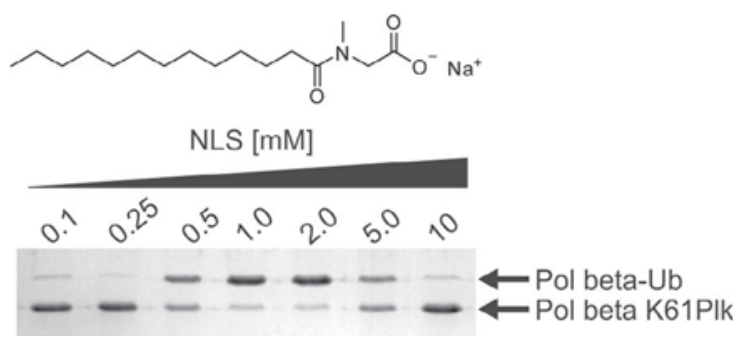

Figure 3. Effect of negatively charged alkane surfactants on CuAAC. (A) Effect of different alkyl sulfonates up to concentrations of $10 \mathrm{mM}$ or $3 \mathrm{mM}$ (for dodecyl sulfonate) to the click reactions. (B) Effect of $N$-lauroylsarcosine (NLS). Positions of Pol beta and ubiquitylated Pol beta are indicated.

To analyze the influence of the length of the alkane chain on conjugation efficiency, we tested several different, commercially available alkane sulfonates (Fig. 3A). We found that with decreasing length of the alkane chain, the stimulating effect of the alkyl sulfonate on product formation decreased as well. In more detail, while upon addition of dodecyl sulfonate a high pro duct yield was already observed at a concentration of $0.25 \mathrm{mM}$, with decyl sulfonate increased yields were only observed at a con centration of $2 \mathrm{mM}$ or higher. For octyl and hexyl sulfonates, only little effects on the click reaction were detectable within the con centration range tested. By using $\mathrm{Na}_{2} \mathrm{SO}_{4}$, we also checked, if a neg atively charged molecule without any alkane chain attached is a useful additive for CuAAC between the proteins tested. However, no effect on product formation was observed (data not shown).

As the results above indicated a correlation between the effi ciency of the click reaction and the charge and the length of the alkyl chain of the additive, we finally tested $N$ lauroylsarcosine (NLS, Fig. 3B). Remarkably, nearly complete conversion of Pol beta to the respective ubiquitin conjugate at concentrations of $1 \mathrm{mM}$ or $2 \mathrm{mM}$ of NLS was found. The effect of NLS was even superior to that of $1 \mathrm{mM}$ SDS. At concentrations of NLS and SDS of $5 \mathrm{mM}$ and higher, product formation was hampered (Fig. 3B). Furthermore, the results obtained with NLS and SDS indicate that while the pos itive effect of alkyl chains on product formation requires the pres ence of a negatively charge head group, its actual identity is of no or little concern.

To obtain evidence that the effect of negatively charged surfac tants on chemical ubiquitylation is not restricted to Pol beta but can be generalized, we determined the effect of the two most effec tive surfactants identified, SDS and NLS, on click reaction mediated formation of ubiquitin dimers (Ub Ub). To do so, we used two ubiquitin variants containing Plk either at position K6 or K48 for conjugation with Ub G76Aha (Fig. 4). In both cases, the surfactants increased di ubiquitin formation upon click reaction with similar efficiency. Interestingly, the concentration of NLS required for opti mal product yield was slightly higher than for Pol beta Ub forma tion ranging between $2 \mathrm{mM}$ and $5 \mathrm{mM}$, whereas for SDS, efficient product formation was observed between $0.5 \mathrm{mM}$ and $2 \mathrm{mM}$. The results obtained for the conjugation of ubiquitin K6Plk are partic ularly remarkable since for this position Ub Ub formation was ini tially found to be rather inefficient ${ }^{55}$ (Fig. 4A).

To investigate whether the employed surfactant concentrations interfere with protein folding, we tested the stability of the pro teins used in presence of different concentrations of SDS and NLS by CD spectroscopy (Fig. 5A and B). For both, ubiquitin and Pol beta, a slight increase of the minimum at $207 \mathrm{~nm}$ was observed upon addition of SDS, indicating a slight increase of $\alpha$ helical sec ondary structure. Stabilization of $\alpha$ helical secondary structures by SDS was described for ubiquitin ${ }^{61}$ and other proteins ${ }^{62}$ before. As the changes are only minor compared to the changes observed for the fully denatured proteins, we conclude that the SDS concen trations used to enhance CuAAC efficiencies $(0.251 \mathrm{mM})$ do not induce significant protein unfolding. This is in line with previous findings that ubiquitin adopts a native structure in presence of SDS at concentrations of up to $2 \mathrm{mM} .^{61,63}$ Similarly, for NLS concen trations of up to $2 \mathrm{mM}$, no changes in the $\mathrm{CD}$ spectra of both pro teins were observed demonstrating intact secondary structure upon addition of this surfactant (higher concentrations of NLS could not be tested due to increased absorbance of the sample below $220 \mathrm{~nm}$ ).

To further prove that the concentrations of surfactant used to enhance CuAAC do not influence their functionality, we tested a ubiquitin dimer generated in the presence of SDS for its recognition by the ubiquitylation cascade. For this purpose, an E6AP auto ubiquitylation assay was carried out (Fig. 5C), which we have previously used to demonstrate proper folding and recognition of ubiquitin dimers generated by click reaction (note that in previous work, click reactions were performed without SDS). ${ }^{55}$ Accordingly, we generated ubiquitin dimers linked at position $\mathrm{K} 6$ by click 
A
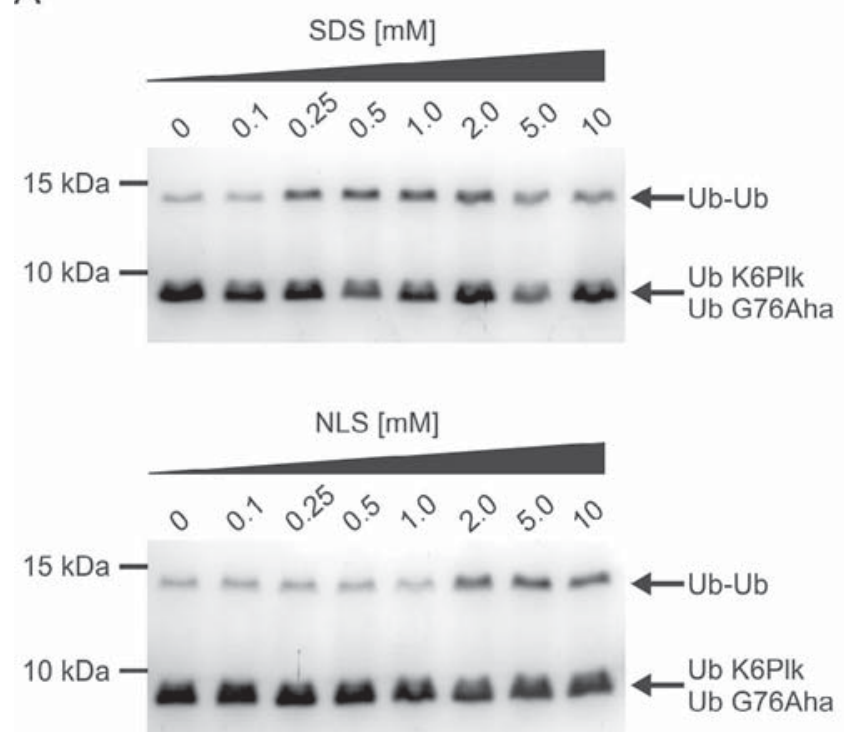

B
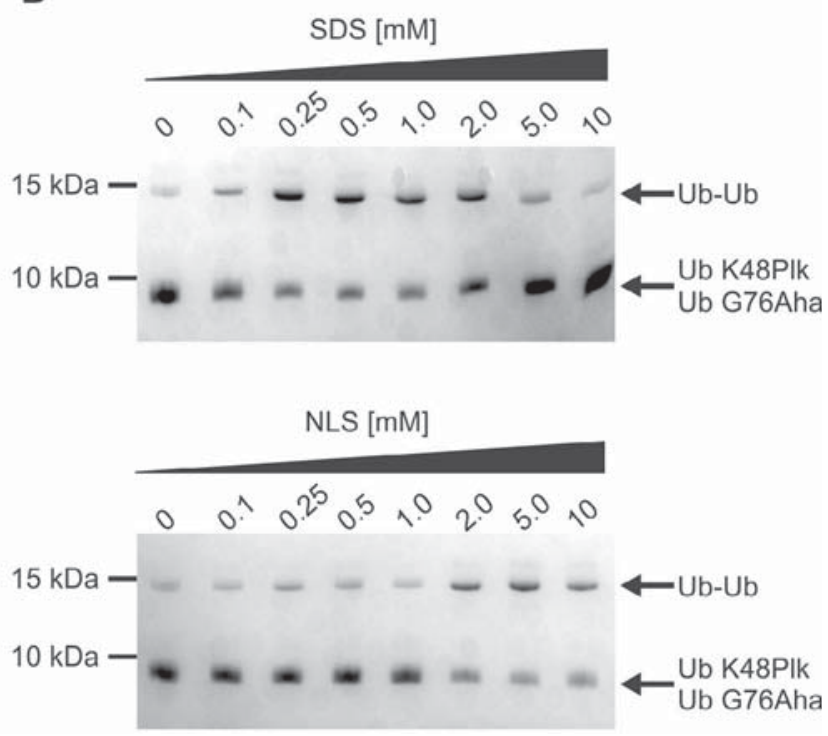

Figure 4. Addition of SDS and NLS increases ubiquitin dimer formation via click reaction in a concentration-dependent manner. Dimer formation of ubiquitin containing an alkyne functionality instead of a lysine at position (A) 6 or (B) 48. For both sites of modification, addition of SDS to the click reaction efficiently increased product formation within a concentration range of $0.25-2 \mathrm{mM}$ while addition of 2-5 mM NLS generated the maximum amount of dimer formation. Running positions of ubiquitin monomers, dimers, and molecular mass markers are indicated.

reaction in presence of $0.5 \mathrm{mM}$ SDS and subsequently purified these by size exclusion chromatography. For both substrates, mono ubiquitin and di ubiquitin, poly ubiquitylation of E6AP was detected (the higher reaction efficiency observed with mono ubiquitin is in line with our previous findings indicating that di ubiquitin is less efficiently used by the ubiquitylation cascade ${ }^{55}$ ). Additionally, di ubiquitylated E6AP, but not mono ubiquitylated E6AP was observed in the reaction with di ubiquitin as substrate. This demonstrates that indeed, di ubiquitin was used for E6AP ubiquitylation. Thus, in line with previously published data ${ }^{64,65}$ the concentration of SDS needed to enhance the click reaction does not significantly interfere with protein folding and function.

\section{Conclusion}

In this study, we investigated the previously reported positive impact of SDS on bioorthogonal protein protein conjugation by CuAAC. We found that this effect is specifically observed with sur factants that exhibit both, a negatively charged head group and an alkane chain of sufficient length. While providing increased confor mational flexibility and thereby accessibility of the reactive groups might play a role in promoting CuAAC, it is presumably not the predominant determinant causing this effect. For all proteins tested both, NLS and SDS, robustly and efficiently increased pro duct formation indicating a general effect of these compounds on the click reactions for chemical ubiquitylation. Interestingly, we found that the optimal concentrations to enhance CuAAC were dif ferent for SDS and NLS and were also dependent on the proteins targeted for ubiquitylation. This indicates that optimal reaction conditions have to be determined for each protein pair studied by titration of the respective surfactant. Importantly, for the pro teins tested, the concentrations of detergent that efficiently enhance conjugation are non denaturing and do not interfere with protein folding and function.

Taking together, these results highlight that addition of non denaturing amounts of SDS or NLS is a straight forward and robust approach to enable efficient and fast click reactions between pro teins with only micromolar concentrations of reactants. Therefore, two major limitations concerning click reaction between proteins have been overcome. Firstly, high concentrations of both, alkyne and azide, or large excess of one reactant, preferably the azide ${ }^{23}$ to accelerate the reaction rate are not required. This is of particu larly importance because increasing the concentration of proteins functionalized with unnatural amino acids is often not possible as their preparation, purification, and/or solubility is limited. Sec ondly, rather long reaction times, which increase the risk of $\mathrm{Cu}$ induced protein oxidation and, thus, functional inactivation, are obsolete. Thus, addition of SDS or NLS represents a major advance for the applicability of $\mathrm{Cu}(\mathrm{I})$ catalyzed click reactions to generate protein protein conjugates in high yields for further functional analysis.

\section{Experimental section}

\subsection{Expression and purification of Ub G76Aha}

The cDNA coding for human Ub G76Aha (synthesized by GeneArt; the initial ATG codon was omitted) was cloned into pGEX2TK and transformed into methionine auxotrophic Escherichia coli B834 (DE3) as described. ${ }^{57}$ For expression, cells were cultured in $1 \mathrm{~L}$ NMM (for composition see Ref. 67) containing $0.06 \mathrm{mM}$ methionine overnight at $37^{\circ} \mathrm{C}$. Subsequently, cells were harvested and resuspended in $100 \mathrm{ml} \mathrm{NMM}$ containing $0.5 \mathrm{mM}$ azidohomoala nine (Iris Biotech). After incubation at $37^{\circ} \mathrm{C}$ for $30 \mathrm{~min}, 1 \mathrm{mM}$ IPTG was added to induce expression for $6 \mathrm{~h}$ at $37^{\circ} \mathrm{C}$. The cells were harvested by centrifugation and resuspended in $25 \mathrm{~mL}$ lysis buffer ( $1 \times$ PBS, $1 \%$ Triton $X 100)$. Lysis was performed by sonication and the clarified lysate was loaded onto a GST TrapFF ${ }^{\mathrm{TM}}$ column (GE HEALTHCARE). After addition of $10 \mathrm{U}$ thrombin, the column was incubated at room temperature overnight. Subsequently, Ub G76Aha was eluted with $1 \times$ PBS and purity of Ub G76Aha fractions was confirmed by SDS PAGE. The protein was stored at $4{ }^{\circ} \mathrm{C}$.

\subsection{Expression and purification of Ub K6Plk and Ub K48Plk}

Expression of Plk modified ubiquitin (Ub) was performed via amber codon suppression. The cDNA coding for Ub K6TAG or Ub K48TAG deriving from site directed mutagenesis was cloned 
A

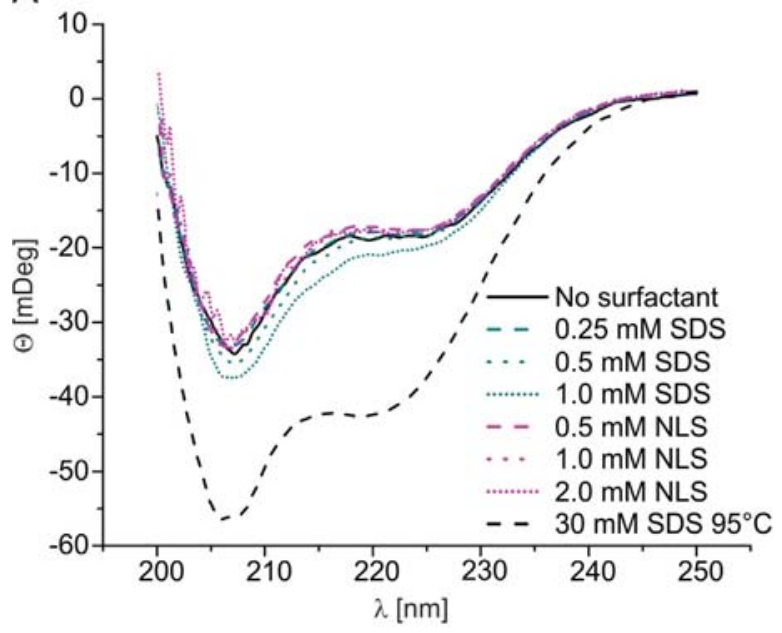

C
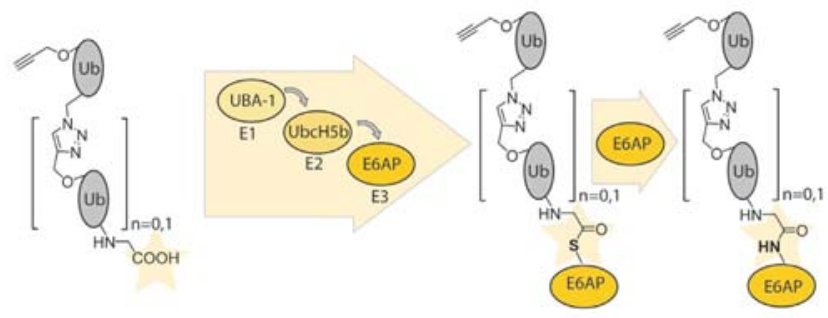

B
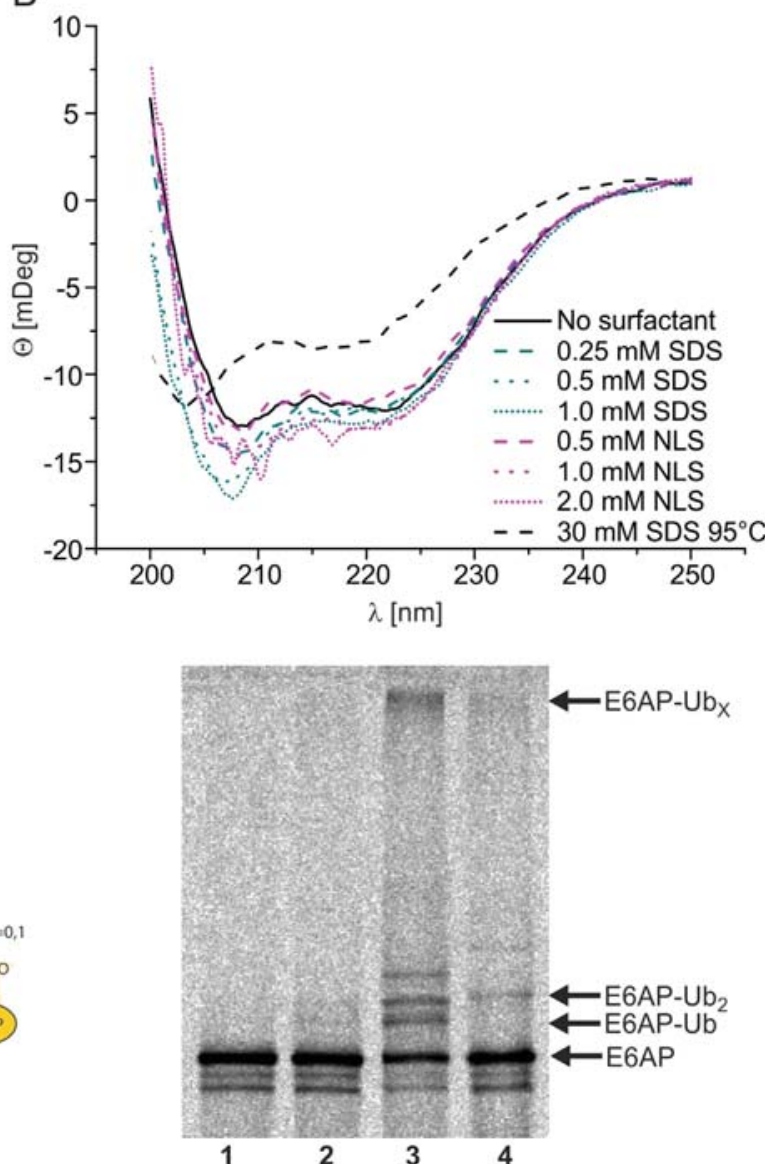

Figure 5. Surfactant concentrations used do not interfere with structure and function of the proteins studied. (A) Analysis of the secondary structure of ubiquitin or (B) Pol beta upon addition of different concentrations of SDS (magenta plots) or NLS (petrol plots) by CD spectroscopy. The spectra of the proteins without surfactant or of the fully denatured proteins (addition of $30 \mathrm{mM}$ SDS followed by heat denaturation) are shown with solid or dashed black lines, respectively. (C) Synthesized K6-linked ubiquitin dimers are utilized by the ubiquitylation cascade. The attachment of ubiquitin to ${ }^{35}$ S-labeled E6AP, which is the E3 ligase and also the substrate in this reaction, was monitored. ${ }^{66}$ The in vitro ubiquitylation assay (schematic view; left panel) was performed in absence of ubiquitin either at $4{ }^{\circ} \mathrm{C}$ or $25^{\circ} \mathrm{C}$ (right panel; lanes 1 and 2 ) or in the presence of mono- and di-ubiquitin at $25^{\circ} \mathrm{C}$ (right panel; lanes 3 and 4). Covalent attachment of ubiquitin or di-ubiquitin results in a shift of E6AP to higher molecular masses. Positions of free E6AP and its mono-, di-, and poly-ubiquitylated forms are indicated.

into a pET11a plasmid which also contained an expression cassette for tRNA ${ }^{\text {Pyl }}{ }^{55,56}$ E. coli BL21 (DE3) was co transformed with this plasmid and the pRSFDuet1 vector carrying the PylRS gene. Cells were cultured in LB medium supplemented with the appropriate antibiotics until an $\mathrm{OD}_{600}$ of 0.3 was reached. At this stage $1 \mathrm{mM}$ Plk was added to the culture. At an $\mathrm{OD}_{600}$ of 0.8 , expression was induced by addition of $1 \mathrm{mM}$ IPTG. Expression proceeded for $14 \mathrm{~h}$ at $37{ }^{\circ} \mathrm{C}$ and cells were harvested by centrifugation. After resuspen sion in lysis buffer ( $25 \mathrm{mM} \mathrm{NaOAc}$, $\mathrm{pH} 4.5$ ) cells were lysed by son ication and the clarified lysate was heated to $75^{\circ} \mathrm{C}$ for $30 \mathrm{~min}$. After centrifugation, the supernatant was further purified via cation exchange chromatography using a $\operatorname{HiTrap}^{\mathrm{TM}}$ SP HP column (GE HEALTHCARE) with a linear gradient from $0 \mathrm{M}$ to $1 \mathrm{M} \mathrm{NaCl}$ in $20 \mathrm{mM}$ NaOAc pH 4.0. Purity of Plk modified Ub fractions was analyzed by SDS PAGE followed by Commassie blue staining and samples were stored after dialysis in $25 \mathrm{mM}$ Tris, $100 \mathrm{mM} \mathrm{NaCl}$, $\mathrm{pH} 7.5$ at $4{ }^{\circ} \mathrm{C}$.

\subsection{Expression and purification of Pol beta K61Plk}

Expression of Plk modified DNA polymerase (Pol) beta was performed as previously described. ${ }^{56}$ E. coli BL21 (DE3) was co transformed with a pET11a plasmid containing an expression cassette for tRNA ${ }^{\text {Pyl }}$ and a codon optimized cDNA of $N$ terminally $\mathrm{His}_{6}$ tagged Pol beta K61Plk and the pRSFDuet 1 vector carrying the PylRS gene. Cells were cultured in LB medium supplemented with the appropriate antibiotics until an $\mathrm{OD}_{600}$ of $0.3 .1 \mathrm{mM}$ Plk was added and cells were cultured until an $\mathrm{OD}_{600}$ of 0.8 before $1 \mathrm{mM}$ IPTG was added and expression was allowed to proceed for $14 \mathrm{~h}$ at $37^{\circ} \mathrm{C}$. Subsequently, cells were harvested, resuspended in freshly prepared lysis buffer (20 mM Tris $\mathrm{HCl}$ pH 7.9, $150 \mathrm{mM}$ $\mathrm{NaCl}, 1 \mathrm{mM}$ PMSF, $5 \mathrm{mM}$ imidazole) and lysed by sonication. Clarified lysate was purified by affinity chromatography using a HisTrapTM column with a linear gradient from $5 \mathrm{mM}$ imidazole to $500 \mathrm{mM}$ imidazole. Pol beta containing fractions were pooled, diluted 1:6 with buffer (20 mM Tris $\mathrm{HCl} \mathrm{pH} 7.0)$ and $\mathrm{pH}$ was corrected to 7.0. The solution was loaded onto a HiTrapTM SP HP column (GE HEALTHCARE) and further purified by ion exchange chromatography with a linear gradient from $50 \mathrm{mM} \mathrm{NaCl}$ to $1 \mathrm{M}$ $\mathrm{NaCl}$ in $20 \mathrm{mM}$ Tris $\mathrm{HCl}$, pH 7.0 over 15 column volumes. Fractions containing pure Pol beta were pooled, dialyzed against $20 \mathrm{mM}$ Tris, $100 \mathrm{mM} \mathrm{NaCl}, 1 \mathrm{mM}$ TCEP, $1 \mathrm{mM}$ EDTA, 10\% (wt/v) glycerol, pH 7.5 and protein concentration was determined by absorption spec troscopy. Glycerol was added to a final concentration of 50\% (wt/v) and samples were stored at $20^{\circ} \mathrm{C}$.

\subsection{Click reaction of Ub G76Aha and Pol beta K61Plk}

$5 \mu \mathrm{M}$ Pol beta K61Plk was mixed with a 510 fold molar excess of Ub G76Aha and supplemented with $20 \mathrm{mM}$ NaAc pH 5.0, $1 \mathrm{mM}$ 
TCEP, $10 \mu \mathrm{M}$ TBTA, $1 \mathrm{mM} \mathrm{CuSO}_{4}$ and the respective detergent. Final concentrations of detergent ranging from 0 to $10 \mathrm{mM}$ were tested. In order to prevent copper induced protein oxidation, reaction ves sels were flushed with argon multiple times. Reactions were allowed to proceed for $1 \mathrm{~h}$ at $4{ }^{\circ} \mathrm{C}$. Then, reactions were stopped by addition of $10 \mathrm{mM}$ EDTA. Product formation was analyzed via SDS PAGE followed by Coomassie blue staining.

\subsection{Click reaction and purification of ubiquitin dimers}

$5 \mu \mathrm{M}$ Ub K6Plk or Ub K48Plk were mixed with a 5 fold molar excess of Ub G76Aha and supplemented with $20 \mathrm{mM}$ Tris $\mathrm{pH} 8.0$, $5 \mathrm{mM} \mathrm{Cu}(\mathrm{MeCN})_{4} \mathrm{BF}_{4}, 10 \mathrm{mM}$ THPTA, and the respective detergent. Final concentrations of detergent ranging from 0 to $10 \mathrm{mM}$ were tested. Reactions were allowed to proceed for $1 \mathrm{~h}$ at $4{ }^{\circ} \mathrm{C}$. Then, reactions were stopped by addition of $50 \mathrm{mM}$ EDTA. Product for mation was analyzed via SDS PAGE and Coomassie blue staining. For preparative generation of ubiquitin dimers linked via K6, click reaction was performed with $0.5 \mathrm{mM}$ SDS. Samples were applied on a Superdex 75 10/300 GL column with $10 \mathrm{mM}$ Tris, pH 7.9, $300 \mathrm{mM} \mathrm{NaCl}$. Fractions containing pure dimer were pooled, dialyzed against water and lyophilized. For further experiments, ubiquitin dimers were dissolved in $25 \mathrm{mM}$ Tris, $\mathrm{pH} 7.5,50 \mathrm{mM} \mathrm{NaCl}$.

\subsection{CD spectroscopy}

Either $0.5 \mathrm{mg} / \mathrm{ml}$ wild type ubiquitin (Sigma) or $0.2 \mathrm{mg} / \mathrm{ml}$ Pol beta K61Plk were mixed in $25 \mathrm{mM}$ Tris $\mathrm{HCl}, \mathrm{pH} 7.5,50 \mathrm{mM} \mathrm{NaCl}$ with different concentrations of SDS or NLS. After incubation at $4{ }^{\circ} \mathrm{C}$ for $1 \mathrm{~h}$, far UV CD spectra from 250 to $200 \mathrm{~nm}$ were recorded using a Jasco J 815 CD spectrometer. To additionally measure a spectrum of fully denatured ubiquitin and Pol beta, the proteins were mixed with $30 \mathrm{mM}$ SDS and heated for $5 \mathrm{~min}$ at $95{ }^{\circ} \mathrm{C}$ before measurement.

\subsection{Ubiquitylation assay}

Ubiquitylation assays were performed as described. ${ }^{68}$ In brief, ubiquitin activating enzyme E1 (UBA1) and E6AP (E3 ligase) were expressed in the baculovirus system. The ubiquitin conjugation enzyme E2 (UbcH5b) was bacterially expressed. Ubiquitylation reactions contained $25 \mathrm{ng}$ of UBA1, $25 \mathrm{ng}$ of UbcH5b, $100 \mathrm{ng}$ bac ulovirus expressed E6AP and $0.5 \mu \mathrm{L}$ rabbit reticulocyte lysate translated ${ }^{35} \mathrm{~S}$ labeled E6AP (to allow detection of E6AP by autora diography) in a total reaction volume of $20 \mu \mathrm{l}$. Ubiquitin variants were supplied in a final concentration of $12.5 \mu \mathrm{g} / \mathrm{mL}$ (mono ubiquitin) and $25 \mu \mathrm{g} / \mathrm{mL}$ (K6 linked di ubiquitin). In addition, reac tions contained $25 \mathrm{mM}$ Tris $\mathrm{pH} 7.5,50 \mathrm{mM} \mathrm{NaCl}, 1 \mathrm{mM}$ DTT, $2 \mathrm{mM}$ ATP and $4 \mathrm{mM} \mathrm{MgCl}_{2}$. After incubation at $25^{\circ} \mathrm{C}$ for $2 \mathrm{~h}$, the reac tions were quenched by addition of sample buffer (final concentra tion: $50 \mathrm{mM}$ Tris $\mathrm{HCl} \mathrm{pH} 6.8,0.8 \%$ (w/v) SDS, 8\% (w/v) glycerol, $2.5 \%(\mathrm{v} / \mathrm{v}) \beta$ mercaptoethanol). Samples were boiled and separated by SDS PAGE. ${ }^{35}$ S labeled E6AP was detected via autoradiography.

\section{Acknowledgements}

We gratefully acknowledge funding by the Deutsche Forschungsgemeinschaft within the SFB 969 'Chemical and Biolog ical Principles of Cellular Proteostasis' and the Carl Zeiss Stiftung (stipend to T.S.). We also acknowledge financial support by the Konstanz Research School Chemical Biology.

\section{References and notes}

1. Hein, C. D.; Liu, X. M.; Wang, D. Pharm. Res. 2008, 25, 2216.

2. Kolb, H. C.; Finn, M. G.; Sharpless, K. B. Angew. Chem., Int. Ed. 2004, 2001, 40.
3. Kolb, H. C.; Sharpless, K. B. Drug Discovery Today 2003, 8, 1128.

4. Moses, J. E.; Moorhouse, A. D. Chem. Soc. Rev. 2007, 36, 1249.

5. Huisgen, R. Angew. Chem. 1963, 75, 742.

6. Rostovtsev, V. V.; Green, L. G.; Fokin, V. V.; Sharpless, K. B. Angew. Chem., Int. Ed. 2002, 41, 2596.

7. Tornoe, C. W.; Christensen, C.; Meldal, M. J. Org. Chem. 2002, 67, 3057.

8. Gierlich, J.; Burley, G. A.; Gramlich, P. M.; Hammond, D. M.; Carell, T. Org. Lett 2006, 8, 3639.

9. Jang, H.; Fafarman, A.; Holub, J. M.; Kirshenbaum, K. Org. Lett. 1951, 2005, 7.

10. Punna, S.; Kaltgrad, E.; Finn, M. G. Bioconjugate Chem. 2005, 16, 1536.

11. Speers, A. E.; Adam, G. C.; Cravatt, B. F. J. Am. Chem. Soc. 2003, 125, 4686.

12. Wang, Q.; Chan, T. R.; Hilgraf, R.; Fokin, V. V.; Sharpless, K. B.; Finn, M. G. J. Am Chem. Soc. 2003, 125, 3192.

13. Binder, W. H.; Sachsenhofer, R. Macromol. Rapid Commun. 2008, 29, 952.

14. Helms, B.; Mynar, J. L.; Hawker, C. J.; Frechet, J. M. J. Am. Chem. Soc. 2004, 126, 15020.

15. Ladmiral, V.; Mantovani, G.; Clarkson, G. J.; Cauet, S.; Irwin, J. L.; Haddleton, D. M. J. Am. Chem. Soc. 2006, 128, 4823.

16. Li, H.; Cheng, F.; Duft, A. M.; Adronov, A. J. Am. Chem. Soc. 2005, 127, 14518.

17. Wu, P.; Malkoch, M.; Hunt, J. N.; Vestberg, R.; Kaltgrad, E.; Finn, M. G.; Fokin, V. V.; Sharpless, K. B.; Hawker, C. J. Chem. Commun. (Camb.) 2005, 5775.

18. Lee, L. V.; Mitchell, M. L.; Huang, S. J.; Fokin, V. V.; Sharpless, K. B.; Wong, C. H. J. Am. Chem. Soc. 2003, 125, 9588.

19. Lewis, W. G.; Green, L. G.; Grynszpan, F.; Radic, Z.; Carlier, P. R.; Taylor, P.; Finn, M. G.; Sharpless, K. B. Angew. Chem., Int. Ed. 2002, 41, 1053.

20. Mocharla, V. P.; Colasson, B.; Lee, L. V.; Röper, S.; Sharpless, K. B.; Wong, C.-H.; Kolb, H. C. Angew. Chem., Int. Ed. 2005, 44, 116.

21. Sharpless, K. B.; Manetsch, R. Expert Opin. Drug Discov. 2006, 1, 525.

22. Whiting, M.; Muldoon, J.; Lin, Y.-C.; Silverman, S. M.; Lindstrom, W.; Olson, A. J.; Kolb, H. C.; Finn, M. G.; Sharpless, K. B.; Elder, J. H.; Fokin, V. V. Angew. Chem., Int. Ed. 2006, 45, 1435.

23. Bock, V. D.; Hiemstra, H.; van Maarseveen, J. H. Eur. J. Org. Chem. 2006, 2006, 51.

24. Horne, W. S.; Stout, C. D.; Ghadiri, M. R. J. Am. Chem. Soc. 2003, 125, 9372.

25. Horne, W. S.; Yadav, M. K.; Stout, C. D.; Ghadiri, M. R. J. Am. Chem. Soc. 2004, 126,15366

26. Pedersen, D. S.; Abell, A. Eur. J. Org. Chem. 2011, 2011, 2399.

27. Tischler, M.; Nasu, D.; Empting, M.; Schmelz, S.; Heinz, D. W.; Rottmann, P.; Kolmar, H.; Buntkowsky, G.; Tietze, D.; Avrutina, O. Angew. Chem., Int. Ed. 2012, 51,3708

28. Valverde, I. E.; Bauman, A.; Kluba, C. A.; Vomstein, S.; Walter, M. A.; Mindt, T. L. Angew. Chem., Int. Ed. 2013, 52, 8957.

29. Behbehani, G. R.; Saboury, A. A.; Taleshi, E. J. Mol. Recognit. 2008, 21, 132.

30. Tullis, J. S.; VanRens, J. C.; Natchus, M. G.; Clark, M. P.; De, B.; Hsieh, L. C.; Janusz, M. J. Bioorg. Med. Chem. Lett. 2003, 13, 1665.

31. Brik, A.; Muldoon, J.; Lin, Y.-C.; Elder, J. H.; Goodsell, D. S.; Olson, A. J.; Fokin, V. V.; Sharpless, K. B.; Wong, C.-H. ChemBioChem 2003, 4, 1246.

32. Giffin, M. J.; Heaslet, H.; Brik, A.; Lin, Y.-C.; Cauvi, G.; Wong, C.-H.; McRee, D. E.; Elder, J. H.; Stout, C. D.; Torbett, B. E. J. Med. Chem. 2008, 51, 6263.

33. Velazquez, S.; Alvarez, R.; Perez, C.; Gago, F.; De Clercq, E.; Balzarini, J.: Camarasa, M. Antiviral Chem. Chemother. 1998, 9, 481.

34. Genin, M. J.; Allwine, D. A.; Anderson, D. J.; Barbachyn, M. R.; Emmert, D. E.; Garmon, S. A.; Graber, D. R.; Grega, K. C.; Hester, J. B.; Hutchinson, D. K.; Morris, J.; Reischer, R. J.; Ford, C. W.; Zurenko, G. E.; Hamel, J. C.; Schaadt, R. D.; Stapert, D. Yagi, B. H. J. Med. Chem. 2000, 43, 953.

35. Veronese, F. M.; Harris, J. M. Adv. Drug Deliv. Rev. 2008, 60, 1

36. Hafrén, J.; Zou, W.; Córdova, A. Macromol. Rapid Commun. 2006, 27, 1362.

37. Liebert, T.; Hänsch, C.; Heinze, T. Macromol. Rapid Commun. 2006, 27, 208.

38. Gramlich, P. M. E.; Wirges, C. T.; Manetto, A.; Carell, T. Angew. Chem., Int. Ed. 2008, 47, 8350.

39. Eger, S.; Castrec, B.; Hübscher, U.; Scheffner, M.; Rubini, M.; Marx, A. ChemBioChem 2011, 12, 2807.

40. Frisch, B.; Hassane, F.; Schuber, F. In Liposomes; Weissig, V., Ed.; Springer Humana Press, 2010; Vol. 605, p 267.

41. Schneider, T.; Schneider, D.; Rösner, D.; Malhotra, S.; Mortensen, F.; Mayer, T. U.; Scheffner, M.; Marx, A. Angew. Chem., Int. Ed. 2014, 53, 12925.

42. Weikart, N. D.; Mootz, H. D. ChemBioChem 2010, 11, 774.

43. Godula, K.; Rabuka, D.; Nam, K. T.; Bertozzi, C. R. Angew. Chem., Int. Ed. 2009, 48, 4973.

44. Sun, X. L.; Stabler, C. L.; Cazalis, C. S.; Chaikof, E. L. Bioconjugate Chem. 2006, 17 52.

45. Ju, J.; Kim, D. H.; Bi, L.; Meng, Q.; Bai, X.; Li, Z.; Li, X.; Marma, M. S.; Shi, S.; Wu, J.; Edwards, J. R.; Romu, A.; Turro, N. J. Proc. Natl. Acad. Sci. U.S.A. 2006, 103, 19635.

46. Rozkiewicz, D. I.; Gierlich, J.; Burley, G. A.; Gutsmiedl, K.; Carell, T.; Ravoo, B. J.; Reinhoudt, D. N. ChemBioChem 1997, 2007, 8.

47. Steinhagen, M.; Holland-Nell, K.; Meldal, M.; Beck-Sickinger, A. G. ChemBioChem 2011, 12, 2426.

48. Tolstyka, Z. P.; Richardson, W.; Bat, E.; Stevens, C. J.; Parra, D. P.; Dozier, J. K.; Distefano, M. D.; Dunn, B.; Maynard, H. D. ChemBioChem 2013, 14, 2464.

49. Speers, A. E.; Cravatt, B. F. Chem. Biol. 2004, 11, 535.

50. Deiters, A.; Cropp, T. A.; Mukherji, M.; Chin, J. W.; Anderson, J. C.; Schultz, P. G. J. Am. Chem. Soc. 2003, 125, 11782.

51. Link, A. J.; Tirrell, D. A. J. Am. Chem. Soc. 2003, 125, 11164.

52. Sommer, S.; Weikart, N. D.; Brockmeyer, A.; Janning, P.; Mootz, H. D. Angew. Chem., Int. Ed. 2011, 50, 9888.

53. Bundy, B. C.; Swartz, J. R. Bioconjugate Chem. 2010, 21, 255. 
54. Eger, S.; Scheffner, M.; Marx, A.; Rubini, M. In Ubiquitin Family Modifiers and the Proteasome; Dohmen, R. J., Scheffner, M., Eds.; Humana Press, 2012; Vol. 832, p 589.

55. Eger, S.; Scheffner, M.; Marx, A.; Rubini, M. J. Am. Chem. Soc. 2010, 132, 16337.

56. Rösner, D.; Schneider, T.; Schneider, D.; Scheffner, M.; Marx, A. Nat. Protoc. 2015, 10, 1594.

57. Schneider, D.; Schneider, T.; Rösner, D.; Scheffner, M.; Marx, A. Bioorg. Med. Chem. 2013, 21, 3430.

58. Hjelmeland, L. M. Proc. Natl. Acad. Sci. U.S.A. 1980, 77, 6368.

59. Navarrete, R.; Serrano, R. Biochim. Biophys. Acta, Biomembr. 1983, 728, 403.

60. Gelamo, E. L.; Tabak, M. Spectrochim. Acta, Part A Mol. Biomol. Spectrosc. 2000, $56,2255$.
61. Schneider, G. F.; Shaw, B. F.; Lee, A.; Carillho, E.; Whitesides, G. M. J. Am. Chem. Soc. 2008, 130, 17384.

62. Parker, W.; Song, P. S. Biophys. J. 1992, 61, 1435.

63. Shaw, B. F.; Schneider, G. F.; Whitesides, G. M. J. Am. Chem. Soc. 2012, 134, 18739.

64. Nielsen, M. M.; Andersen, K. K.; Westh, P.; Otzen, D. E. Biophys. J. 2007, 92, 3674.

65. Otzen, D. E. Biophys. J. 2002, 83, 2219.

66. Nuber, U.; Schwarz, S. E.; Scheffner, M. Eur. J. Biochem. 1998, 254, 643.

67. Budisa, N.; Steipe, B.; Demange, P.; Eckerskorn, C.; Kellermann, J.; Huber, R. Eur. J. Biochem. 1995, 230, 788.

68. Nuber, U.; Schwarz, S.; Kaiser, P.; Schneider, R.; Scheffner, M. J. Biol. Chem. 1996, 271, 2795 